\title{
La fuite des Dieux
}

Norval Baitello

\section{Loin au delà de la grammaire :}

ne pas expliquer, mais confondre.

La formation de sociétés complexes se situe très au-delà de la question grammaticale du singulier et du pluriel. La réduction du temps ou son accélération semblent avoir exigé d'énormes efforts dans la re-création des rapports à l'autre, au dissemblable et, à partir de là, dans la redéfinition du soi. L'époque des expurgations, l'époque de la purification et du nivellement, I'homogénéisation par les processus habituels d'acculturation ou d'élimination physique, ayant été supprimées, n'étaient plus possibles. La création de l'Autre dans les moules de I'Un appartenait à un autre temps historique, un temps pensé comme espace, un temps pour ainsi dire territorialisé et, donc, domestiqué. L'unité était garantie par l'occupation d'un temps-territoire construit sans hâte, au rythme d'une histoire proposée par les dieux. La première conséquence de l'accélération colonisatrice est la fuite des dieux. Le "synchronos ", fondamental pour n'importe quelle technologie, disparaît. L'espace s'ouvre alors au « diaballein ». C'est là que naît le germe du multiculturalisme : mort de l'unique, émergence d'un tout fait d'unités disparates, élaborée seulement à partir des autres. Le Moi est toujours un Autre. L'unité minimale est plurielle, le singulier est fragment, fraction, rupture et, donc, élément sans fonction. A la place de l'ordre agencé, du "synchronos ", le syncrétisme entre en scène, négation de la théologie une et ordonnatrice. Le temps des colonisés, accéléré, ne suffit plus pour pratiquer des épurations ethniques, il ne permet pas que se développe une dialectique de vainqueur et de vaincu, de maître et d'esclave. La logique est celle de l'inversion, les vaincus sont les vrais vainqueurs, les employés les véritables patrons, les 
subalternes vraiment les supérieurs. Dans la logique de l'anthropophagie, le vainqueur dévore le vaincu pour incorporer ses qualités reconnaissant ainsi sa force, son caractère, sa bravoure et son courage : le vainqueur devient volontairement le vaincu.

C'est, pourrait-on dire, dans cet état d'esprit que, vers les années soixante, soixante-dix, l'animateur de télévision, Abelardo Barbosa, le « chacrinha » disait, au milieu d'un déluge de klaxons, de jolies filles de toutes races à demi nues et de morceaux de morue et de chou jetés sur le public :

"Je ne suis pas ici pour expliquer, je suis ici pour confondre ".

\section{Le temps sauvage :}

la nouvelle anthropophagie.

Les colonisateurs, en essayant de créer dans les colonies un temps encore plus ordonné que dans les métropoles, entraînèrent une croissante rébellion du temps luimême et un processus de régression vers les étapes antérieures à la domestication du temps au moyen du territoire. Ainsi, le temps retourne à l'état sauvage, pré-territorial, et le territoire, en raison de la fuite des dieux, perd son identité première et devient la terre de l'autre, bien que cet autre soit moi. C'est la logique du multiculturalisme : une distanciation autocritique par rapport à l'autre et une approximation altérocritique en direction de soi-même. Paradoxal dans son essence, schizophrène dans son for intérieur, et pour cette raison précise, particulièrement sain, le multiculturalisme est une anthropophagie permanente : se dévorer soi-même pour sauvegarder l'autre. C'est pourquoi le mouvement moderniste brésilien proclama en mai 1928 , lors de la première édition/dentition de son manifeste anthropophage : " seule, l'anthropophagie nous unit. Socialement. Économiquement. Philosophi-quement ». Signé : Oswald de Andrade et daté de « An 374 de la déglutition de l'Évêque Sardinha* ». 


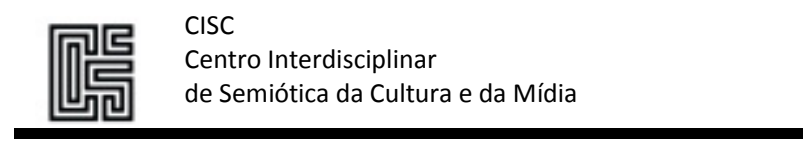

* L'Évéque évangélisateur Sardinha fut dévoré par des Indiens en 1656.

In: Revue Noire, 22. 